\title{
IS FACTOR V LEIDEN A RISK FACTOR FOR FETAL LOSS?
}

\author{
Petr Dulíček ${ }^{1}$, Ladislav Chrobák${ }^{1}$, Ivo Kalousek ${ }^{2}$, Lenka Pešavová ${ }^{3}$, Miroslav Pecka ${ }^{1}$, Pravoslav Stránský4
}

University Teaching Hospital in Hradec Králové: Department of Clinical Haematology ${ }^{1}$, Department of Clinical Biochemistry $^{3}$; Charles University in Prague, Faculty of Medicine in Hradec Králové: Department of Obstetrics and Gynecology ${ }^{2}$, Department of Medical Biophysics ${ }^{4}$

Summary: A successful pregnancy is dependent on the development of adequate placental circulation. The abnormalities of placental vasculature may result in a number of gestational pathologies, including fetal loss. The aim of our study was to determine whether women with $\mathrm{f} V$ Leiden are at an increased risk of pregnancy loss. For this purpose we assessed three groups of women. In a prospective group we examined 30 females with spontaneous abortions for $\mathrm{f} V \mathrm{Leiden}$. In a retrospective group we assessed the frequency of abortions in 80 women (172 pregnancies) with $\mathrm{f} V$ Leiden ( 72 heterozygous, 8 homozygous) from 57 unrelated families. In a control group we evaluated the frequency of abortions in 45 women without $\mathrm{f}$ V Leiden. Factor V Leiden was found in 3\% of women in the 1st group. Fetal loss occurred in 10\% of women in the $2^{\text {nd }}$ group and in $9 \%$ in the 3 rd group. Factor V Leiden was not found to be a risk factor for fetal loss in our study group.

Key words: Placental infarction; Hypercoagulable state; APC resistance; F V Leiden; Venous thromboembolism; Fetal loss

This project was supported by Grant No. 3691-3 of IGA Czech Ministry of Health.

\section{Introduction}

Deep venous thrombosis is a serious but rare vascular complication during pregnancy and puerperium and pulmonary embolism is one of the most important causes of maternal mortality $(10,15)$.

The physiological changes in haemostasis increase the risk of thromboembolism in pregnancy (16). The risk is even higher in women with congenital thrombophilia (6,13). In 1993 Dahlbäck et al. (9) identified a new mechanism causing inherited thrombophilia, characterized by a poor anticoagulant response to activated protein $\mathrm{C}$ (APC resistance-APC-R). The molecular defect underlying this phenomenon was identified as an amino acid substitution at the cleavage site of factor $\mathrm{V}$ gene (1691 G to A) (2). Point mutation in the $\mathrm{f} \mathrm{V}$ gene is responsible for APC-R in more than $90 \%$ of cases (14).APC-R without $\mathrm{V} V$ Leiden is called „acquired“ APC-R and is usually found in the association with pregnancy (19),use of oral contraceptives (20) and in cancers (12).This imbalance of the haemostatic equilibrium increase the life long risk of thrombosis 5-10 fold in heterozygotes and 50-100 fold in homozygotes (7). In Caucasians, APC-R is the most common of the known inherited risk factors for venous thromboembolism (VTE) $(8,25)$. Women with APC-R and f V Leiden have 8 fold increased risk of VTE in pregnancy (18).
A successful outcome of pregnancy requires an efficient uteroplacental vascular system. Congenital thrombophilia may lead to hypercoagulable state. This state can cause placental infarctions. Placental infarctions can result in the following complications in pregnancy: abortion, intrauterinne fetal growth retardation, premature delivery, preeclampsia and intrauterinne death (4). Placental thrombosis was previously described not only in women with lupus anticoagulant, but also in women with Antithrombin III (AT III), protein $\mathrm{C}$ and protein $\mathrm{S}$ deficiencies (23).

The reported early loss rate among recognized pregnancies is between $12 \%-15 \%$ (24). Approximately $5 \%$ of women have the experience of two or more consecutive abortions (3). The recurrent fetal loss defined by at least three successive abortions affects $1 \%$ to $2 \%$ of women at the reproductive age (3).

The aim of our study was to assess the association of APC-R and f V Leiden with spontaneous abortion. This relationship was not known at the time of the beginning of our study. In case that a positive relationship will be found, we want to consider the usefulness of prophylactic anticoagulation treatment in the next pregnancy. As a miscarriage was considered fetal loss before $28^{\text {th }}$ week of pregnancy, as a stillbirth a termination of pregnancy after $28^{\text {th }}$ week. As mentioned above, the recurrent fetal loss was defined by at least three successive abortions. 


\section{Materials and methods}

In 1996 we examined 500 blood donors (309 males,191 females) to get prevalence of APC-R in the East Bohemian region. This prevalence has been found to be $1,6 \%$. We assessed the association of APC-R and $\mathrm{f}$ V Leiden with spontaneous fetal loss in three cohorts of women.

\section{l. A prospective group}

Thirty women admitted to our hospital for spontaneous or recurrent fetal loss were tested for APC-R and $\mathrm{f} V$ Leiden. All females completed the questionnaire about family and personal history of VTE. Characteristics of this group are shown in table 1 . All women were also tested for protein $\mathrm{C}$, protein S,AT III levels, for the presence of lupus anticoagulant (LA) and anticardiolipin antibody (ACA).

\section{A retrospective group}

In this group we assessed the course of 172 pregnancies in 80 women with

APC-R and $\mathrm{f} V$ Leiden (72 heterozygous, 8 homozygous) from 57 unrelated families. Diagnosis of APC-R and f V Leiden was made either in the laboratory work-up of women with personal history of thrombosis event or in the laboratory work-up of family members of individuals with personal history of thrombosis and with APC-R and f V Leiden. Characteristics of this group are shown in table 2. All women with history of fetal loss were also tested for ACA,LA,protein C,protein S and AT III.

\section{A control group}

In this group we evaluated the course of 104 pregnancies in 45 women without APC-R and $\mathrm{V} V$ Leiden from 42 unrelated families. These women are relatives of individuals with history of thrombotic event and with diagnosis of APC-R and $\mathrm{f} V$ Leiden. Characteristics of this group are shown in table 3 . All women with the history of pregnancy loss were tested for ACA, LA, protein C, protein S and AT III as well.

Methods: Blood samples were collected by venipuncture into plastic tubes containing either $1 / 10$ volume of $3,8 \%$ sodium citrate for coagulation assays or $1 / 10$ volume of 0,5 $M$ sodium EDTA for DNA extraction. After centrifugation $(15$ min. at $2500 \mathrm{G}$ ) for prothrombin time (PT), activated partial thromboplastin time (APTT) and AT III assays or after double centrifugation $(+10 \mathrm{~min}$ at $1500 \mathrm{G}$ ) for protein $\mathrm{C}$, protein S,APC-R and LA assays, citrated plasma was either analyzed immediately (PT,APTT,LA) or stored at $70^{\circ} \mathrm{C}$ until analyzed (AT III, protein C, protein S,APC-R). APC-R was determined by COATEST APC RESISTANCE kit (Chromogenix). Low response for APC-R was defined as $\mathrm{SR}<2,05$ ( $\mathrm{SR}=$ sensitivity ratio-clot time $\mathrm{APTT}+\mathrm{APC}$ to APTT without APC).

Protein $\mathrm{C}$ and protein $\mathrm{S}$ were determined by coagulation assays using STACLOT PROTEIN $\mathrm{C}$ and STACLOT PROTEIN S kits. AT III was determined by chromogenix assays using STA-STACHROM AT III kit. All kits are from STAGO Diagnostics. To detect LA, the following assays were performed: PT, APTT (PTT Automate, Stago D.), APTT with high sensitivity to LA (PTT-LA, STAGO D.), TTIT (Tissue Thromboplastin Inhibition Time), dRVVT (diluted Russell's Viper Venom Time). A solidphase immunoassays technique was used to quantify anticardiolipin levels. IgG level $>10 \mathrm{U} / \mathrm{ml}$ and $\operatorname{IgM}$ level $>7 \mathrm{U} / \mathrm{ml}$ were considered as positive results. PCR method was used for $\mathrm{f} \mathrm{V}$ Leiden determination.

Statistical analysis: Data were evaluated by software program NCSS 6.0.1. using Fisher's test for categorial variables.

\section{Results}

\section{l. The prospective group}

In the group of 30 women admitted to the hospital we obtained the results which are shown in table 4. Stillbirths did not occur in any of these women. LA,protein C, protein $\mathrm{S}$, AT III deficiencies were not detected either. Frequency of APC-R has been found to be 7\% (1\%-22\%), frequency of f V Leiden 3\% (0\%-17\%).

\section{The retrospective group}

By the assessment of 172 pregnancies in 80 women with f V Leiden we got the results which are shown in table 5. Stillbirths did not occur in any of these women. Protein C, protein $\mathrm{S}$ and AT III deficiencies were not found in any of 8 women with abortions. Antiphospholipid syndrome was diagnosed in one woman with recurrent abortions (positivity of LA and ACA). Frequency of women with abortion in this group is $10 \%(4 \%-19 \%)$. Frequency of abortions is $8 \%$ $(4 \%-13 \%)$

\section{The control group}

The results in cohort of women without $f \mathrm{~V}$ Leiden are shown in table 6. Stillbirths did not occur in any of these women. Protein C, protein S,AT III deficiencies were not found in any of 4 women with spontaneous abortions either. Frequency of women with abortion in this group is $9 \%$ ( $2 \%-21 \%)$, and frequency of abortions is $6 \%(2 \%-12 \%)$. Using Fisher's exact test we have not found statistical difference $(p=0,1)$ between frequency of women with abortions in the retrospective group and in the control group. We have not proven statistical difference $(p=0,63)$ between frequency of abortions in women in these groups either.

Tab. 1: Characteristics of females with spontaneous or recurrent fetal loss.

\begin{tabular}{|l|l|}
\hline Number (No.) of women (w.) & 30 \\
\hline Mean age (yrs.) & 28 \\
\hline Age range (yrs.) & $21-41$ \\
\hline No. of pregnancies & 43 \\
\hline Mean age of pregnant w. (yrs) & 26 \\
\hline Age range of pregnant w. (yrs.) & $21-41$ \\
\hline
\end{tabular}


Tab. 2: Characteristics of females with APC-R and f V Leiden.

\begin{tabular}{|l|l|}
\hline No. of w. & 80 \\
\hline Mean age (yrs.) & 43 \\
\hline Age range (yrs.) & $23-70$ \\
\hline No. of pregnancies & 172 \\
\hline Mean age of pregnant w. (yrs.) & 25 \\
\hline Age range of pregnant w. (yrs.) & $18-37$ \\
\hline
\end{tabular}

Tab. 3: Characteristics of females without APC-R and f V Leiden.

\begin{tabular}{|l|l|}
\hline No. of w. & 45 \\
\hline Mean age (yrs.) & 43 \\
\hline Age range (yrs.) & $24-72$ \\
\hline No. of pregnancies & 104 \\
\hline Mean age of pregnant w. (yrs.) & 24 \\
\hline Age range of pregnant w. (yrs.) & $19-38$ \\
\hline
\end{tabular}

Tab. 4: The results in the prospective group.

\begin{tabular}{|l|l|}
\hline No. of w. with 1 spontaneous abortion & 21 \\
\hline No. of w. with 2 spontaneous abortions & 6 \\
\hline No. of w. with recurrent abortions & 3 \\
\hline Mean week of abortion & 10 \\
\hline Week range of spontaneous abortion & $7-27$ \\
\hline No. of w. with APC-R & 2 \\
\hline No. of w. with f V Leiden & 1 \\
\hline
\end{tabular}

Tab. 5: Frequency of abortions in women with APC-R and f V Leiden.

\begin{tabular}{|l|l|}
\hline No. of w. with 1 spontaneous abortion & 4 \\
\hline No. of w. with 2 spontaneous abortions & 3 \\
\hline No. of w. with recurrent abortions & 1 \\
\hline Mean week of abortion & 10,5 \\
\hline Week range of spontaneous abortion & $7-18$ \\
\hline
\end{tabular}

Tab. 6: Frequency of abortions in women without APC$\mathrm{R}$ and $\mathrm{f} \mathrm{V}$ Leiden.

\begin{tabular}{|l|l|}
\hline No. of w. with 1 spontaneous abortion & 3 \\
\hline No. of w. with 2 spontaneous abortions & 0 \\
\hline No. of w. with recurrent abortions & 1 \\
\hline Mean week of abortions & 11 \\
\hline Week range of spontaneous abortion & $7-18$ \\
\hline
\end{tabular}

\section{Discussion}

Since 1996 several reports have been published about the relationship between $\mathrm{f} \mathrm{V}$ Leiden and fetal loss. These studies assessed either the association of $\mathrm{f} V$ Leiden with recurrent fetal loss or the association with miscarriages and stillbirths. EPCOT study (European Prospective Cohort on Thrombophilia) is the largest study which analyzed the risk of fetal loss in women with known thrombophilia. Researchers found that the odds ratios were 3,6 (95\% CI $1,4-9,4)$ for stillbirths and $1,3(95 \%$ CI $0,94-1,71)$ for miscarriages. The odds ratios were 2,0 (0,5-1,77) for stillbirths and
$0,9(0,5-1,5)$ for miscarriages in women-carriers of f V Leiden (21). On the other in Berkane's study, f V Leiden was not found to be a common risk for stillbirths (1). The most recent prospective study performed in Sweden, comprising 2480 women with APC-R in early pregnancy, eluciated its obstetrics consequences. The presence of APC-R was unrelated to adverse pregnancy outcome apart from an 8 fold increased risk of VTE (18).

Three recent case control studies documented a significantly increased prevalence of factor $\mathrm{V}$ Leiden mutation in women with recurrent fetal loss $(22,11,5)$. The increased prevalence was not found in study done by Kotwal (17). The discrepancies in the results may be explained by differences in selection criteria, including the ethnic origin of the study populations. Other potential causes for recurrent fetal loss, like chromosomal abnormalities, autoimmune disorders, endocrinologic diseases, infections and anatomic abnormalities should be eliminated as well. F V Leiden is a mild risk factor for thrombosis and is also a mild risk factor for recurrent pregnancy loss (3) but the majority of women who are carriers of $\mathrm{f} V$ Leiden will not experience a recurrent fetal loss.

\section{Conclusion}

Resistance to activated protein $\mathrm{C}$ and $\mathrm{f} \mathrm{V}$ Leiden were not the risk factors for miscarriage and stillbirth in our study group. They have not been found to be the risk factors for recurrent fetal loss either. Prophylactic anticoagulant treatment is not indicated in women with APC-R and $\mathrm{f} \mathrm{V}$ Leiden and with the history of fetal loss in their next pregnancies.

\section{References}

1. Berkane A, Verdy E, Heim A et al. Does the $\mathrm{Q}^{506}$ mutation of factor $\mathrm{V}$ contribute to fetal loss or stillbirth? Thromb Haemost 1997; Suppl. 1:759-60

2. Bertina RM, Koeleman BPC, Koster T et al. Mutation in blood coagulation factor V associated with resistance to activated protein C. Nature 1994;369:64-7.

3. Brenner B. Inherited thrombophilia and pregnancy loss. Thromb Haemost 1999;82:634-40.

4. Brenner B, Mandel H, Lanir A et al. Activated protein C resistance can be associated with recurrent fetal loss. Br J Haematol 1997;97:551-4

5. Brenner B, Sarig G, Weiner Z, Younis J, Blumenfeld Z, Lanir N. Thrombophilic polymorphism in women with fetal loss. Blood 1998;92(Suppl. 1):558a

6. Conard J, Horellou MH, VanDreden P, Lecompte T, Samama M. Thrombosis and pregnancy in congenital deficiencies in AT III, protein $\mathrm{C}$ or protein $\mathrm{S}$. Thromb Haemost 1990;63:319-20.

7. Dahlbäck B. Resistance to activated protein C, the $\operatorname{Arg}^{506}$ to Gln mutation in the factor V gene, and venous thrombosis. Thromb Haemost 1995;73:739-42.

8. Dahlbäck B. Inherited thrombophilia: resistance to activated protein $\mathrm{C}$ as a pathogenic factor of venous thromboembolism. Blood 1995;85:607-14

9. Dahlbäck B, Carlsson M, Svensson PJ. Familial thrombophilia due to a previously unrecognized mechanism characterized by poor anticoagulant response to activated protein C; prediction of a cofactor to activated protein C. Proc Natl Acad Sci U.S.A 1993;90:1004-8

10. Franks AL, Atrash HK, Lawson HW, Colberg KS. Obstetrical pulmonary embolism mortality. United States 1970-85. Am J Public Health 1990;80:720-2.

11. Grandone E, Margaglione M, Colaizzo D et al. Factor V Leiden is associated with repeated and recurrent unexplained fetal losses. Thromb Haemost 1997;77:822-4.

12. Green D, Maliekel K, Sushko E et al. Activated protein C resistance in cancer patients. Thromb Haemost 1997;Suppl.1:316.

13. Hellgren M, Tengborn L, Abildgaard U. Pregnancy in women with congenital antithrombin III deficiency: Experience of treatment with heparin and antithrombin. Gynecol Obstet Invest 1982;14:127-41.

14. Hillarp A, Dahlbäck B. Activated protein C resistance. Vessels 1997;3:3-10. 
15. Högberg U. Maternal mortality in Sweden. Thesis,Umea,Sweden 1985;118.

16. Kjellberg U, Andersson NE, Rosen S, Tengborn L, Hellgren M. APC resistance and other haemostatic variables during pregnancy and puerperium. Thromb Haemost 1999;81:527-31.

17. Kotwal J, Saxena R, Mohanty S et al. APC resistance in recurrent fetal loss in the Indian population. Br J Haematol 1998; 103:588.

18. Lindqvist PG, Svensson PJ, Maršál K, Grenner L, Luterkort M, Dahlbäck B. Activated protein $\mathrm{C}$ resistance (f $\mathrm{V} \mathrm{Q}^{506}$ ) and pregnancy. Thromb Haemost 1999;81:532-7

19. Meinardi JR, Henkens CMA, Heringa et al. Acquired APC resistance related to oral contraceptives and pregnancy and its possible implications for clinical practise. Blood Coag Fibrinol 1997;8:152-4.

20. Olivieri O, Friso S, Manzato F et al. Resistance to activated protein $\mathrm{C}$ in healthy women taking oral contraceptives. Br J Haematol 1995;91:465-70.

21. Preston FE, Rosendaal FR, Walker ID et al. Increased fetal loss in women with heritable thrombophilia. Lancet 1996;348:913-16.

22. Ridker PM, Miletich JP, Buring JE et al. Factor V Leiden mutation as a risk factor for recurrent pregnancy loss. Ann Intern Med 1998; 28:1000-3.

23. Sanson BJ, Friedrich PW, Simioni P et al. The risk of abortion and stillbirth in antithrombin-protein $\mathrm{C}$ and protein $\mathrm{S}$ deficient women. Thromb Haemost 1996; $75: 387-8$.
24. Stirrat GM. Recurrent miscarriage I: definition and epidemiology. Lancet 1990;336:673-5.

25. Svensson PJ, Dahlbäck. Resistance to activated protein C as a basis for venous thrombosis. N Engl J Med 1994;330:517-22.

Submitted September 1999

Accepted September 1999.

MUDr.Petr Duliček, University Teaching Hospital, Department of Haematology, 50036 Hradec Králové, Czech Republic. e-mail: dulicek@fnhk.cz 